\title{
History of Mitigating Rolling Contact Fatigue and Corrugation of Railway Rails in Japan - Review
}

\author{
Makoto Ishida ${ }^{\mathrm{a}, *}$ \\ aRailway Engineering Department, Railway Division, Nippon Koei Engineering Consultants. Email: ishida-mk@n-koei.jp
}

\begin{abstract}
Rail is the one of the most important materials to support and guide railway vehicles safely and smoothly. Since rail suffers from various interacting forces and environmental atmosphere, wear and fatigue pose large problems with wheel and rail. Hence, wear and fatigue of wheel and rail have been studied so far to keep running safety and some level of riding comfort of vehicle taking into account track maintenance cost in the world. In this review, the history of theory and practice of rail maintenance in Japanese railways is described focusing on rolling contact fatigue (RCF) corrugation of rails caused by dynamic rolling friction at wheel/rail interface. In particular, "squat" mainly callled in UK or "rail surface shelling" called in Japan which is one of typical fatigue phenomenon for steel wheel-on-rail system and rail corrugations caused by dynamic lateral friction and vertical loading at sharp curves and/or long wavelength of rail corrugation caused by longitudinal roll-slip or stick-slip excited by the resonance of unsprung mass of bogie vertical vibration supported by track stiffness. In addition, the practice of countermeasure for RCF defect of squat, preventive grinding, and countermeasure for top of low rail corrugation, top of low rail lubrication "Friction Moderating System" are described. Also, the possibility of preventing long wavelength of rail corrugation formed in tangential track in undersea tunnel (salty water) enviornment is described.
\end{abstract}

Keywords: Adhesive materials; preventive grinding, rail; rolling contact fatigue; rail corrugations; top of rail lubrication

\section{Introduction}

Rail is the one of the most important materials for rail way infrastructure to support and guide railway vehicles safely and smoothly. Vertical force and lateral force based on typically vehicle weight and dynamic behaviour such as vehicle negotiating curves interact between wheel and rail.

Also, traction force for driving and braking of vehicle interacts between wheel and rail longitudinally. In addition, thermal axial force acts on rail and longitudinal friction force interacts between rail and rail fastening system particularly under continuous welded rail (CWR). Since rail is suffered from such various interacting forces and environmental atmosphere, wear and fatigue pose large problems with wheel and rail. Hence, wear and fatigue of wheel and rail have been studied so far to keep running safety and some level of riding comfort of vehicle taking into account the economical aspect of track maintenance cost. However, the phenomena of wear and fatigue have been understood to obtain better solutions from the practical point of view but not enough from the best practice.

\footnotetext{
${ }^{\star}$ Corresponding author. Tel.: +81-3-5276-2561

1-14-6 Kudonkita, Chiyodaku, Tokyo

102-8539, Japan
}

In this review, rolling contact fatigue $(\mathrm{RCF})$ of rail which is one of typical fatigue phenomenon for steel wheel-onsteel rail system and rail corrugations caused by dynamic lateral friction and vertical loading at sharp curves and/or long wavelength of rail corrugation caused by longitudinal roll-slip or stick-slip excited by the resonance of vertical vibration of unsprung mass of bogie supported by track stiffness.

In addition, the practice of countermeasure for $\mathrm{RCF}$ defect of squat, preventive grinding, and countermeasure for top of low rail (inner rail of two rails of curved track along the axis of radius which is called as low rail due to cant, slope of lateral direction to cancel the centrifugal force caused by running at curved track, set along the curve of track, and high rail is outer rail which is the opposite rail against inner rail called as low rail) corrugation, top of low rail lubrication "Friction Moderating System" are described. Also, the possibility of preventing long wavelength of rail corrugation formed in tangential track in undersea, salty water, tunnel environment is described. 


\section{Rail RCF defects in Japanese Railways}

\subsection{Dark cracks generated in gentle curves}

The Japanese history of RCF defects in rails is described mainly based on some findings and research achievements obtained so far by Railway Technical Research Institute (RTRI) and Japanese railway operators in Japan. Basically RCF defects must have been initiated just after steel wheelon-steel rail system was developed. But the first comprehensive report on RCF defects in rails was written by a research project group in RTRI organized by Japanese National Railways (JNR) in 1952 [1].

At first some defects called "dark cracks" shown in Fig. 1 in those days were observed in gentle curves in San-yo line of JNR. Typical cracks were caused together with head checks as shown in Fig. 1. The naming of dark cracks is based on superficial feature that some part surrounding cracks look dark presumably due to slightly indented surface. Then such dark cracks posed so serious problem that a research project was established to study the mechanism of crack initiation following dark cracks. Those cracks were observed not only in curves but also in tangent tracks. Fig. 2 shows dark cracks take place in tangent tracks.

Shortly afterwards they came to be called shelling and/or rail surface shelling which is named to differentiate gauge corner shelling which is called as one of the typical fatigue defects of rail reported in heavy haul railways [2]. Also, after Hatfield accident [3], gauge corner cracks shown in Fig. 3 were focused on to understand their mechanism and establish some appropriate preventing and/or mitigating measures.

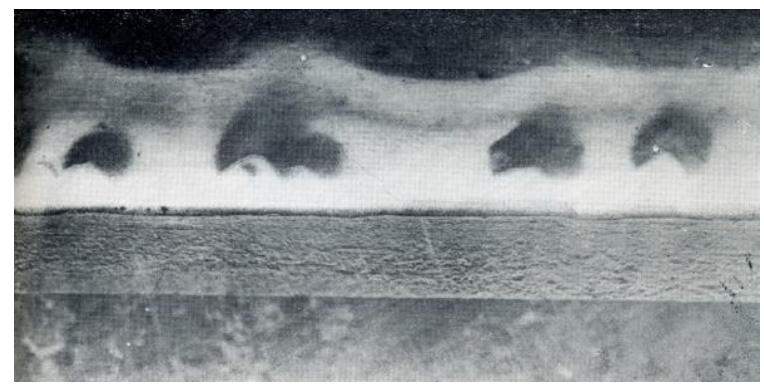

Figure 1. Dark cracks in gentle curves

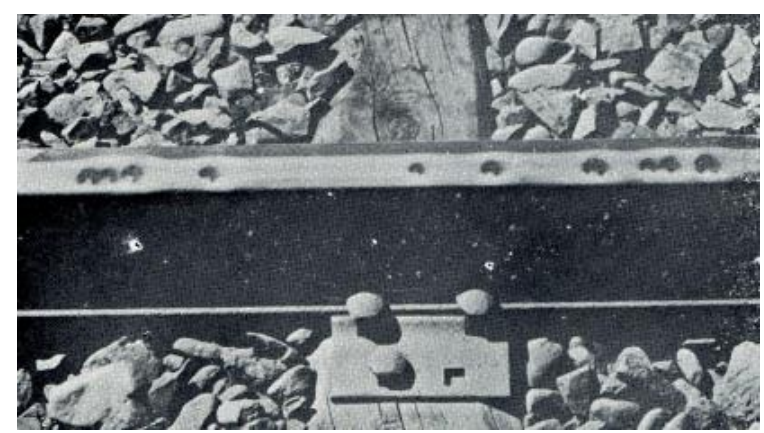

Figure 2. Dark cracks in tangent track

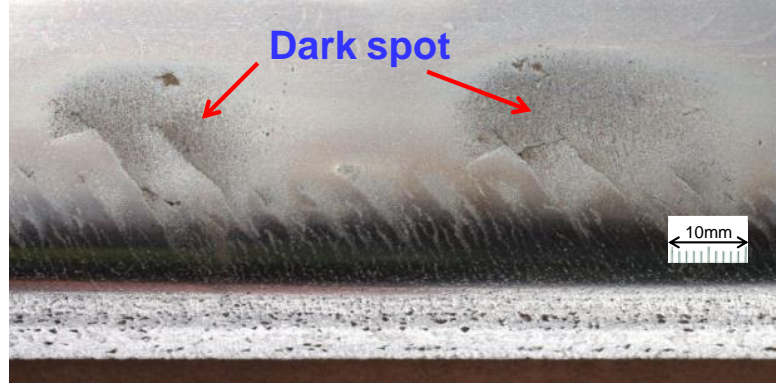

Figure 3. Gauge corner cracks

Considering some features of dark cracks reported in 60 years ago and gauge corner cracks bothering track maintenance engineers nowadays, those cracks look so similar each other not only superficially but also mechanically and metallurgically. Then the mechanism of initiation and propagation of those two cracks may be the same. In addition, gauge corner cracks are classified to rail surface shellings called in Japan or squats called mainly in UK shown in Fig. 4, which is commonly accepted in Japan.

But of course gauge corner cracks are usually caused under head checks generated at gauge corner. And gauge corner cracks are generated not just at gauge corner but slightly close to the centre of rail crown from the gauge corner. The influence of head checks on the initiation of gauge corners has not been clearly understood yet.

Also, gauge corner cracks do not necessarily occur at the location where head checks are observed. Head checks shown in Fig. 5 in the case of as-rolled rails and in Fig.6 in the case of head hardened rails are formed at almost all curves which mean, for example, at transition curves in the case of sharp curves and at circular curves in the case of gentle curves. In these figures, the crack spacing of as-rolled rails is larger than that of head hardened rails, the reason for which is not clearly understood.

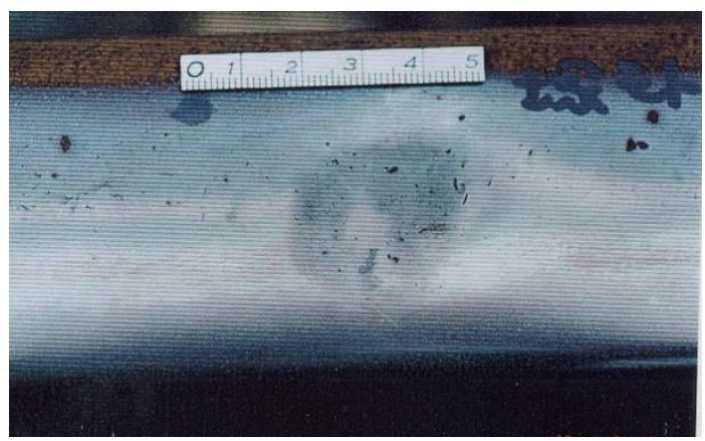

Figure 4. Typical RCF defect "Squat" called in UK and rail surface shelling called in Japan 


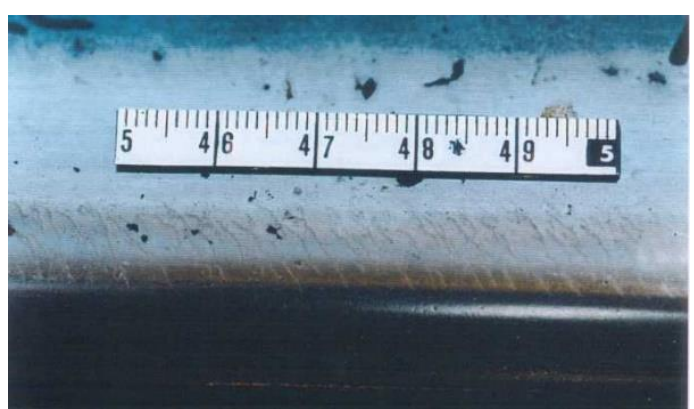

Figure 5. Head checks in as-rolled rail

From the different aspects, some curves whose radius is less than, for example, $800 \mathrm{~m}$ have potentiality of head check formation even if the radius of curvature is very small, because such sharp curves have their transition curves whose radius of curvature changes from small to large, up to tangent tracks, which means head checks can be generated at some location whose radius of curvature should be most suitable for head check generation.

Somehow, the project group studied a lot including laboratory simulation using a small scale rolling contact machine. In the study report written by the project group, dark cracks were likely to be caused at less wear places as a result and in addition water spray from steam locomotives to reduce wear must have had some impact on dark cracks initiation. After that, steam locomotives were changed to electric locomotives because of modernization of traction power, from steam to electricity.

Also, water spray was stopped since the steering performance of electric locomotives should have been improved. Fortunately the number of dark cracks initiation got less than before very much and the problem of dark cracks was settled down as a result.

\subsection{Rail surface shellings generated in Japanese urban metro railways}

In 1970s gauge corner cracks which were called as shellings at that time in Japan as mentioned above posed a large problem in underground railways in Tokyo. Similar to "dark cracks", an investigation committee was established to understand the mechanism of such RCF defects $[4,5]$. In the investigation report, less wear was newly pointed out similar to dark cracks and also the effect of lubrication on the initiation and propagation of RCF defects was pointed out. Then some appropriate amount of gauge face wear of rail to

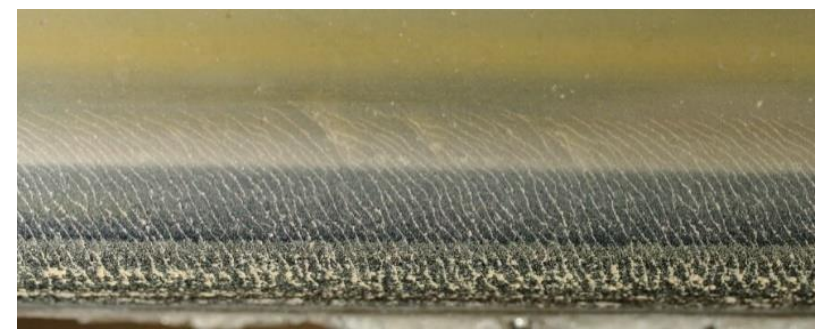

Figure 6. Head checks in head hardened rail mitigate RCF defects was studied. As one of strategies, some head hardened rails were changed to as-rolled rails to increase wear for the purpose of mitigating RCF damage.

Figure 7 shows the variation of wear rate with the radius of curvature focusing on rail grade (AR: as-rolled rail, HT: heat treated rail $=$ head hardened rail) and the initiation of RCF defects. Also, this figure shows the rough tendency of the initiation of RCF defects of both of as-rolled rails and head hardened rails based on wear rate. The both types of rail are suffered from RCF defects, such as squats and/or gauge corner cracks in the case of less wear. It is identified that the larger the radius of curvature is, the less wear rate is, which clearly suggests lateral force and/or steering force causes large wear. For example, considering two sections of Marunouchi line(AR), squats were generated in some sections of Marunouchi line(AR) of less wear rate than the other.

Focusing on Ginza line(HT) and two sections of Marunouchi line(HT), in the least wear rate section of three sections, squats were generated. Less wear is one of key functions for generating squats in both of as-rolled rail and heat treated (head hardened) rail.

\subsection{First stage of rail surface shelling problem in Shinkansen}

First stage of rail surface shelling problem in Tokaido Shinkansen which is the first Japanese high speed line opened in 1964 was raised. Since then most of the rail failures were related to rail welds. But the number of rail surface shellings had been increasing after about 10 years passed since starting its operation. Figure 8 shows the history of the number of rail failures in Tokaido Shinkansen.

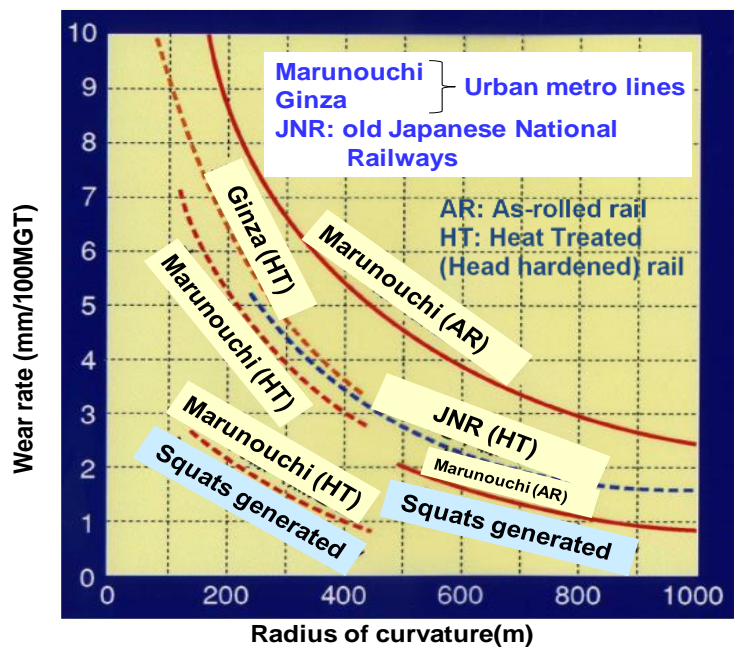

Figure 7. The variation of wear rate with the radius of curvature focusing on rail grade (AR: as-rolled rail, HT: heat treated rail $=$ head hardened rail) and the initiation of RCF defects 


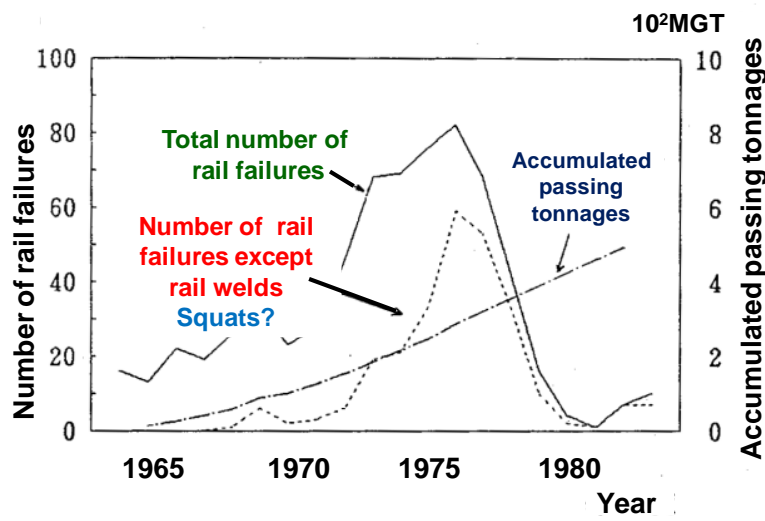

Figure 8. Transition of annual rail failures and accumulated passing tonnages in Tokaido Shinkansen (JIS50T rail)

In this figure, the number of rail failures located not at rail welds was increasing up to 1985 . At that time rail surface shellings were not clearly identified by track maintenance people necessarily because the training for the track maintenance people was not enough to check the rail surface shellings, which means obtained data may have included unsuitable ones. But roughly speaking, the trend of changing the main factor of rail failures from rail welds to rail surface shellings can be identified. However fortunately again, the strategy of improving track structure in Shinkansen was implemented since 1977, which was exchanging JIS 50T rail to JIS 60 rail to reduce the damage of ballast track suffered from impact loads. Hence, the damaged rails of JIS 50T rail were naturally changed under such a strategy.

As a result, the problem of rail surface shellings was superficially settled down again. In a sense this process was very similar to the case of dark cracks, which means the mechanism of crack initiation was not clearly identified so that the effective strategy of mitigation was not obtained, but some strategies to improve other issues changed the situation of damaged rails and the problem of RCF defects was superficially settled down.

\subsection{Second stage of rail surface shelling problems in Shinkansen}

The second Shinkansen line, San-yo Shinkansen, started to operate in 1972. After about 10 years since starting operation, the accumulated passing tonnages reached to 150 to 200 (MGT: Million Gross Tons which is the unit of the number of passing axles multiplied by the weight of an axle to estimate track damage), so that the number of rail surface shellings was getting large. Also, the number of rail surface shellings was getting large in Tokaido Shinkansen after JIS 60 rail installation instead of JIS 50T rail similar to San-yo Shinkansen. Then the study group was newly established again in RTRI in 1985 [6].

It investigated the history of rail surface shellings and the findings related to RCF defects of rails obtained so far were summarized. So that new research programmes including a large twin disc machine for rolling contact fatigue experiments was started. After 10 to 15 years, preventive grinding method was established under the programme for the time being and basically taking into account Shinkansen wheel rail interface condition.

\section{Mechanism of Crack Initiation, Propagation and Mitigation Method}

\subsection{Mechanism of crack initiation and propagation}

The mechanism of crack initiation and propagation has been studied for a long time around the world. In particular, above-mentioned study has not been carried out enough to understand it even if many findings about some other tribological area are taken into account. Also, some important material behaviour and/or parameters such as crack tip stress condition including residual stress distribution have to be understood to develop this research area.

Considering such a status of research front, the author concentrated laboratory simulation using a large twin disc rolling contact machine taking into account the results of roughness contact stress analysis. However, both laboratory experiments and stress analysis for roughness contact have some limitations. Considering such limitation as limited test arrangements and analytical conditions, some appropriate test arrangements and analytical conditions were selected. Also, some findings were obtained from grinding tests and track site monitoring continued for 5 years from 1980 to 1985 in Tokaido Shinkansen. With regard to grinding frequency, every $100 \mathrm{MGT}$ was not enough at least so that the grinding frequency should be expected to be less than 100 MGT, which was considered to decide experimental arrangements and analytical conditions. At that time, Shinkansen suffered from many squats caused mainly on the surface of as-rolled (not head hardened) rail installed in tangent tracks so that analytical conditions and experimental arrangements were discussed on the basis of as-rolled rail of JIS 60, tangent track, the running speed of $200 \mathrm{~km} / \mathrm{h}$ and the average slip ratio of 0.01 , for the time being.

Figure 9 shows the analytical conditions and its results with 2D roughness contact model constructed by Dr. Franklin and Prof. Kapoor under the collaboration between Sheffield Univ. and RTRI[7, 8]. In this figure, with regard to contact pressure between rail disc and wheel disc, roughness contact pressure is much larger than Herzian contact pressure. Also, with regard to Von Mises stress distribution, the maximum of Von Mises stress is located at the surface or very thin layer of the surface under roughness contact and no such a high stress takes place under Hertzian contact. Since this 2D analytical model is elastic and two dimensional, the analytical results don't have agreement with actual wheel-rail contact stress condition but suggest some important tendency of stress distribution to roughly understand the damage of rail material. From the analytical results, the damage of rail should be very large at very thin surface layer, which can lead to the effect of preventive grinding. 


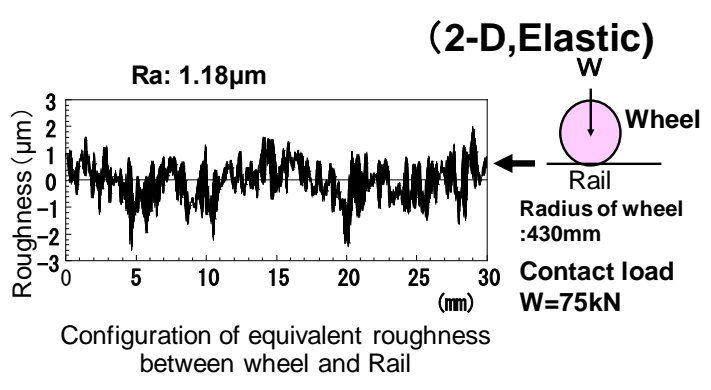

(a) Analytical conditions
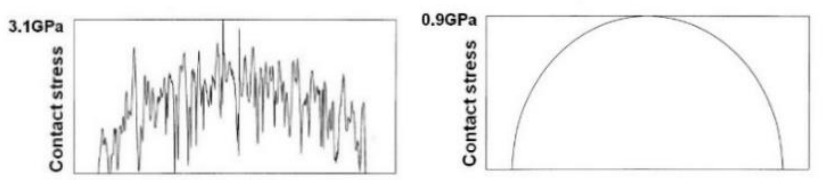

(b) Contact pressure distribution

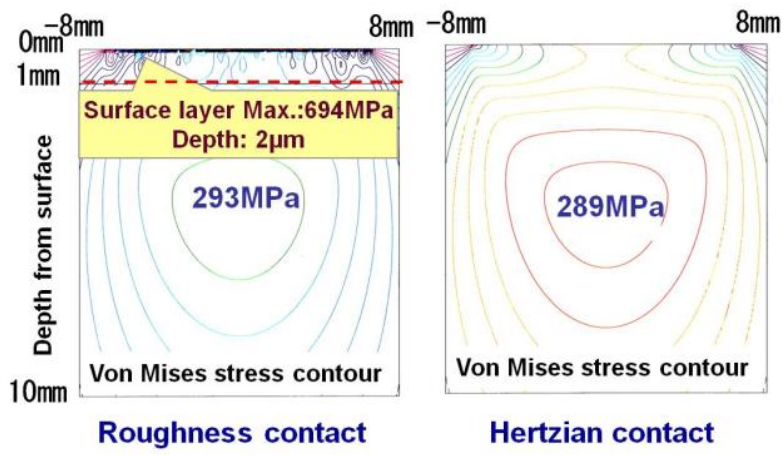

(c) Von Mises stress distribution in rail

Figure 9 . The effect of roughness at wheel/rail contact interface on stress distribution

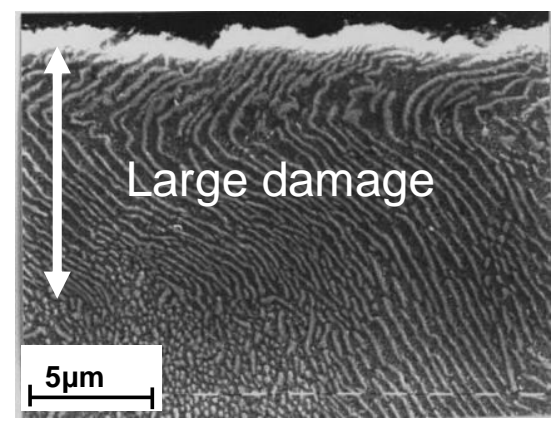

Figure 10. Plastic deformation at the contact surface layer of actual rail material

Figure 10 shows the plastic deformation at the surface of actual rail material. This figure roughly indicates the adequacy of the 2D analytical model and the possibility of RCF crack initiation at the very thin layer. Also, it suggests the possibility that effective grinding thickness should be more than 10 microns and less than $0.1 \mathrm{~mm}$ of rail subsurface combining with analytical results of $2 \mathrm{D}$ roughness model. In addition, focusing on the slip plane of metallic crystal, it is identified that the direction of some specific slip planes is deformed to the same direction plastically under repeated loading [9]. Considering above-mentioned analytical and practical information, the grinding thickness was set to be the only variable parameter and other parameters were constant under the grinding frequency of 50MGT in the experiments using a large twin disc machine. Before grinding experiments, rolling fatigue experiments were carried out to investigate a certain suitable test arrangement for the test machine considering the difference of contact conditions between actual wheel/rail contact and wheel disc / rail disc contact for about more than 5 years [10].

\subsection{Preventive grinding}

After the rolling contact fatigue experiments, the experimental arrangements were decided and the grinding experiments with a key parameter of grinding thickness had been continued for more than 5 years.

Figure 11 shows the results of grinding experiments with the large twin disc machine [11]. In this figure, some regression curves were obtained to estimate the effect of grinding on RCF. Roughly speaking, $0.1 \mathrm{~mm}$ of grinding thickness every 50 MGT has an appropriate effect of grinding to extend the service life of rail up to averagely $800 \mathrm{MGT}$. The adequacy of this preventive grinding method, $0.1 \mathrm{~mm} /$ every $50 \mathrm{MGT}$ was verified in the operation of Tokaido Shinkansen. Roughly speaking, all rails installed in the main line of Tokaido Shinkansen have been ground once a year, about 40 to 50 MGT of annual passing tonnages since 1993. Figure 12 shows the results of detecting rails in the monitoring section of Tokaido Shinkansen [7]. In this figure, the number of defects dramatically decreased since regular preventive grinding started in 1993.

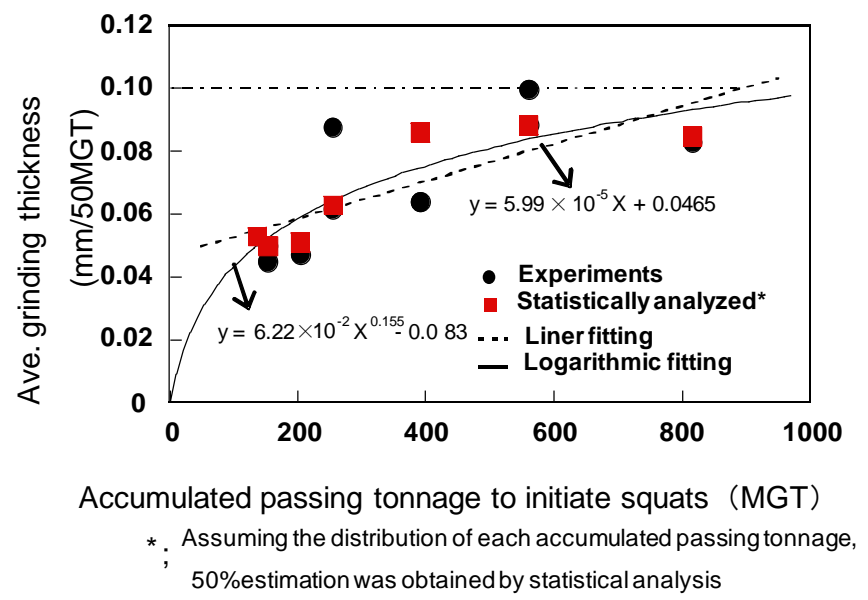

Figure 11. The effect of preventive grinding on accumulated passing tonnages to initiate squats 


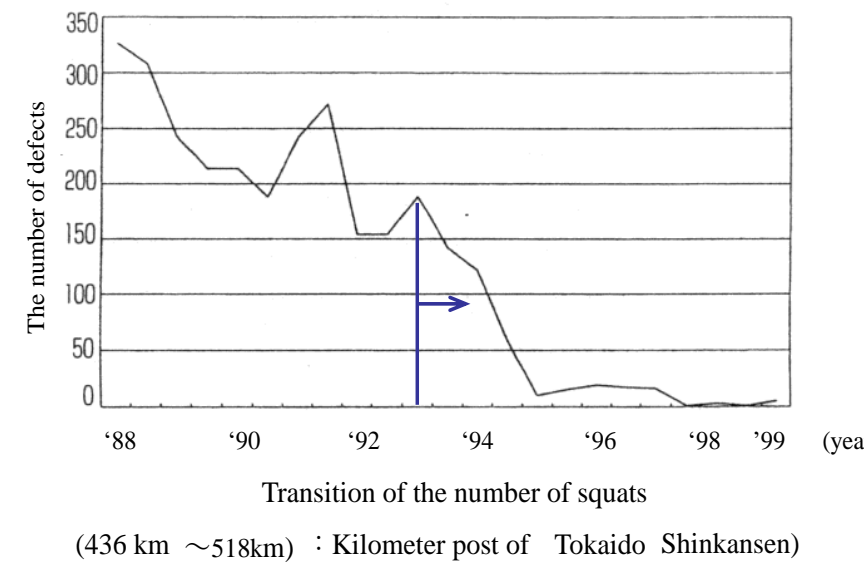

Figure 12. The effect of preventive grinding on mitigating the initiation of RCF defects (after 1993, whole main line of Tokaido was covered with grinding operation)

\subsection{Balance between wear and $R C F$}

In advance of describing the balance between wear and RCF, some interesting research activity and sophisticated achievements in this research area obtained by European and/or other railways than Japanese ones. Almost all railways must have suffered from wear and RCF and have long history of theoretical and practical approach to get the best solution to mitigate wear and RCF. In particular, just before Hatfield accident (Derailment and overturning of train accident caused by rail break due to RCF defects on $17^{\text {th }}$ of Oct., 2000), comprehensive and fundamental research project, Integrated study of rolling CONtact fatigue (ICON) [12], was implemented as one of EU projects from 1997 to 2000 under the leadership of European Rail Research Institute (ERRI). A lot of very good achievements and findings were obtained, but unfortunately before such good deliverables had not been adopted yet, Hatfield accident took place in October, 2000. After the Hatfield accident, RCF was newly focused on to keep the running safety of vehicle. In addition, another EU project "INNOvative TRACK system (IINNOTRACK) [13]" was organised and coordinated by UIC which involved 36 partners from 11 European countries including international railway organisations as well as rail research specialised universities and representatives from rail operators, infrastructure managers and railway track industry suppliers.

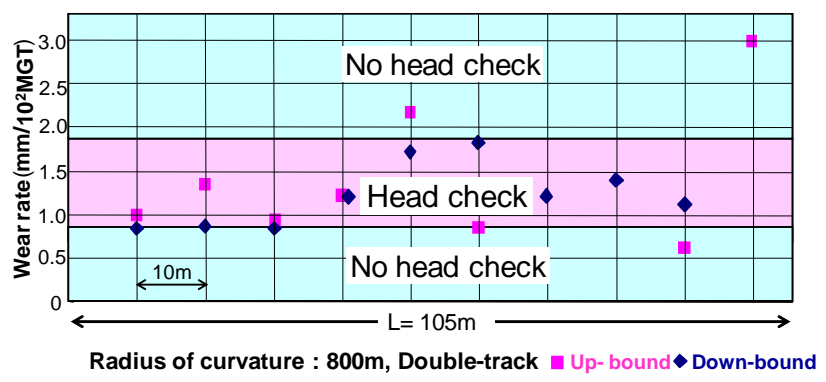

Figure 13. The concept of T-gamma model describing the balance between wear and RCF
After the Hatfield accident, the whole life rail model and T-gamma model were established [14, 15]. Figure 13 shows the concept of T-gamma model. This model is based on friction energy and material strength. According to friction energy, balance between wear and RCF can be evaluated, which is very helpful to select material level and strategy of lubrication and/or grinding. I hope the meaning of damage function should be clearer, for example, RCF function is the rate of crack propagation or plastic deformation and wear function is wear rate and so on. Then the next research subject will be expected to define the damage function.

Also, one of achievements obtained from INNOTRAK is that heat treated rail, head hardened rail, has great effect on mitigating crack propagation of head checks comparing with as-rolled rail. However, considering mitigating and/or preventing gauge corner cracks, heat treated rail may not be always effective in mitigating gauge corner cracks.

The relation between head checks and gauge corner cracks has not been clearly understood yet. As far as Japanese railways are concerned, gauge corner cracks are basically very close to squats, rail surface shellings called in Japan, so that grinding or wear is a key word to mitigate the initiation of gauge corner cracks [16].

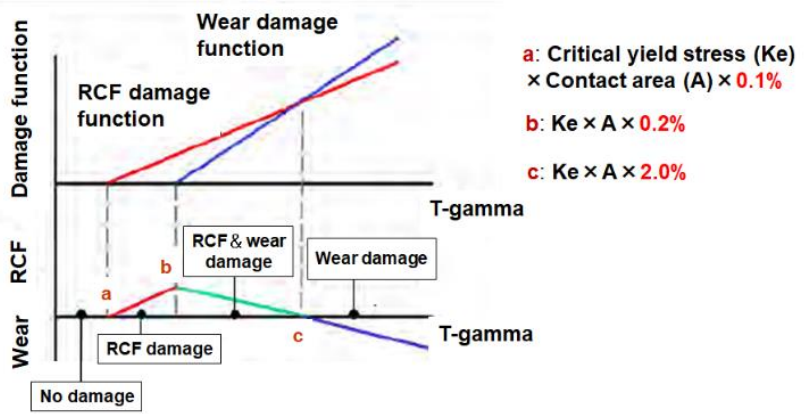

Figure 14. The relation between wear rate and head checks (Head Hardened rails)

Head checks can be generated by the balance between wear and fatigue, which means head checks must be one of RCF defects. Figure 14 shows some range of wear rate where head checks are likely to initiate even if the data are very limited. In the figure, very small amount of wear rate means damage is very less, too, middle range amount of wear rate means suitable balance between wear and RCF for head check initiation, and large amount of wear rate means fatigue damage is not accumulated and worn out.

Finally squat type RCF defects related to white etching layer must be described because this type of defects has been posing a large problem in Japanese conventional narrow gauge tracks [17].

Some reports have been already published in other railways [18, 19]. Figure 15 shows typical squat type RCF defects of white etching layer. Figure 16 shows microstructure of white etching layer.

The typical cause of forming white etching layer is friction heat generated by wheel sliding on rail. Some other causes, for example, large deformation, should surely have an effect on forming white etching layer. 


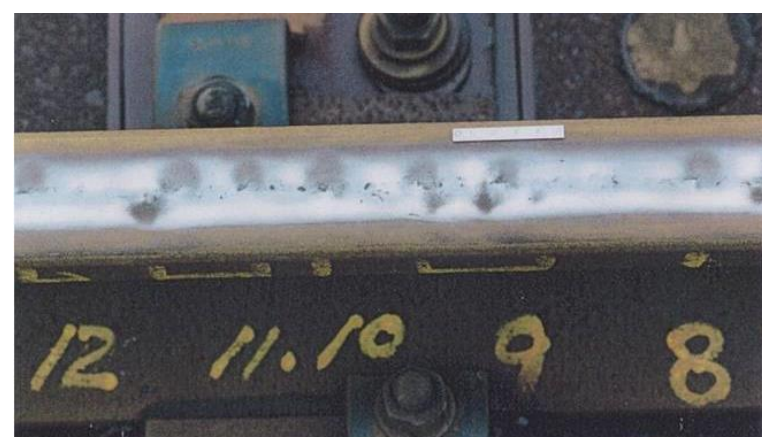

Figure 15. Squat type of RCF defects related to white etching layer
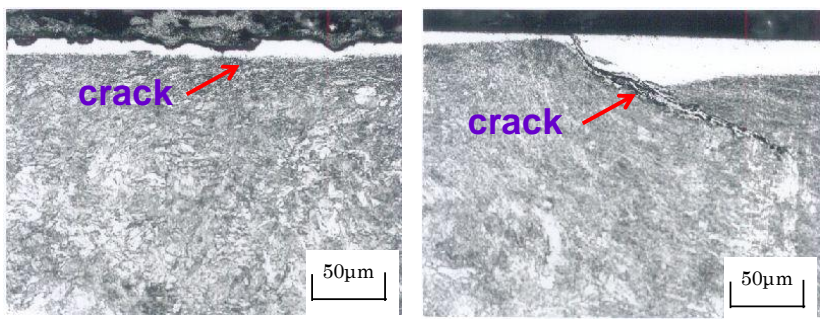

Figure 16. Micro-structure of white etching layer

From the experience of Japanese railways, driving force and/or braking force interacting between wheel and rail, sliding occurs because of less adhesion coefficient ("adhesion coefficient" is used in the field of Railway Engineering and "the maximum coefficient of traction" is generally used in the field of Tribology as the same meaning as adhesion coefficient) than needed potential of friction and heat is generated to change pearlite to martensite from metallurgical point of view. Since Shinkansen's train operation is well controlled to smooth driving and braking much better than narrow gauge conventional train system, almost no report on white etching layer observed in Shinkansen tracks. Considering the mechanism of white etching layer, martensite, formation, it is not easy to prevent wheel-rail sliding perfectly. Considering the current status of this type of defects, early detection is very important to prevent crack initiation from the martensite layer and to grind off fine cracks if already. Some detection system may be promising to mitigate this type of defects.

In addition, bainitic steel rail was developed to prevent squats, rail surface shellings, by modifying material structure [20]. Basically the concept of Japanese bainaitic steel rail is to prevent squat initiation based on the appropriate amount of wear, which means the wear resistance of bainitic steel is less than that of pearlitic steel but its hardness is larger than that of pearlitic steel to prevent large plastic deformation and/or to keep the configuration of rail for better running stability and ride comfort.

Finally considering the balance between wear and RCF, rail type and combination with wheel must be focused on because steel material, hardness and chemical composition and the interaction between rail and wheel have great influence on wear and RCF.

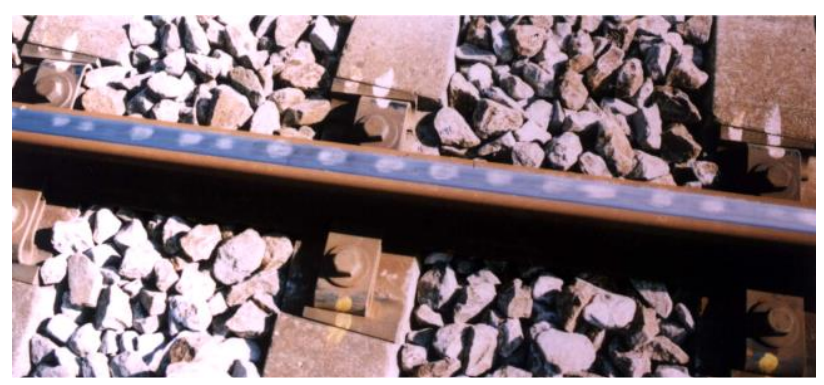

Figure 17. Typical short pitch corrugations formed on low rail surface

\section{Rail Corrugation}

\subsection{Top of low rail corrugations in curved tracks}

Short pitch corrugations on low rails shown in Fig. 17 pose acute problems of noise and track deterioration caused by vibrations excited by interacting between rail and wheel forces.

\section{(1) Influential factors in causing corrugations}

Tassily and Vincent developed a theoretical model of corrugations formed on low rails and high rails at curved tracks in Paris Rapid and Mass Transport Authority (RATP) [21]. They considered: quasi-static curving behaviour; dynamic interactions between the wheel-set and the track; field tests. The frequency ranges of corrugations studied were 50 to $80 \mathrm{~Hz}$ and 250 to $400 \mathrm{~Hz}$. They showed the important relationship between transverse wear rate and roughness. They found two sensitive frequencies at about 60 $\mathrm{Hz}$ and $170 \mathrm{~Hz}$.

The bogie, vehicle and track structures considered in their analysis are not the same as those used in Japan. But the two sensitive frequencies of $60 \mathrm{~Hz}$ and $170 \mathrm{~Hz}$ are very similar to high rail corrugations and low rail corrugations formed in Japanese railways. This means that the transverse wear rate may play an important role on the formation of corrugations. A question arose: which force, lateral creep force or longitudinal creep force, has more influence on the short pitch corrugations? If the lateral creep force is more influential, then dynamic behaviour of a leading axle of a bogie should be investigated rather than a trailing axle. Vehicle running tests and dynamic measurements at a track site were carried out to understand the effect of lateral force and lateral vibration of rail on the formation of corrugations [22].

Also the effect of lubrication on decreasing the lateral force and preventing corrugation formation were studied. Figure 18 shows Q/P (lateral force /vertical force) of low rail measured with strain gauges stuck at rail base flange for lateral force $\mathrm{Q}$ and at rail web for vertical force $\mathrm{P}$ during the vehicle running tests. In the figure, the $\mathrm{Q} / \mathrm{P}$ of the leading axle was most significant and the effect of lubrication on reducing lateral forces was also significant. In addition, Figure 19 shows the first formation of corrugations on a new rail, which locates near the second tie from rail joint in the direction of vehicle running. It is not clearly understood that the coupled vibration between rail joint and wheel give rise 


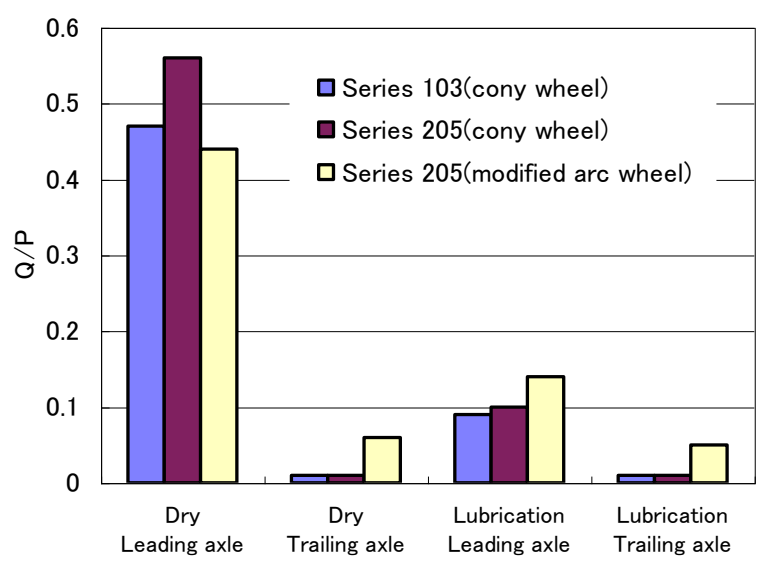

Figure 18. Q/P (lateral force /vertical force) of low rail measured at track site

to corrugations roughly near the second tie from the rail joint first, but almost the same phenomena were very often observed in investigations. It is surely identified that excitation at rail joint gives one of main opportunities of forming corrugations from the findings so far obtained.

Considering the above discussions, the investigation of longitudinal and lateral plastic flow on the surface of some corrugations was carried out [22]. There is little evidence of plastic flow in the longitudinal direction. Most of the plastic flow in Fig. 20 is in the lateral direction. Since plastic flow is greatly influenced by the friction force, plastic flow in the lateral direction indicates the importance of lateral creep forces. The direction of plastic flow (from gauge corner to field corner of the rail) corresponds with the direction of the lateral force on the rail applied by the wheel.

Field investigation shows that lateral creep force and / or longitudinal creep force, and the excitation at rail joints have a great influence on forming corrugations. Also, lateral creep force has greater influence on plastic flow on the surface of corrugations than longitudinal creep force. The excitation of vertical force between rail and wheel at rail joints causes the variation of friction force estimated from the coefficient of friction (COF) multiplied by a resultant of longitudinal and lateral creep forces between wheel and rail. Then, stick-slip phenomenon can be supposed to be induced between a resultant of mainly lateral creep force and longitudinal creep force, and the variation of friction force caused mainly by the vertical excitation at rail joints. This shows that the lateral creep force has a great influence on the formation of low rail corrugations. This may indicate that the behaviour of the leading axle of the bogie should play a more important role than that of the trailing axle.

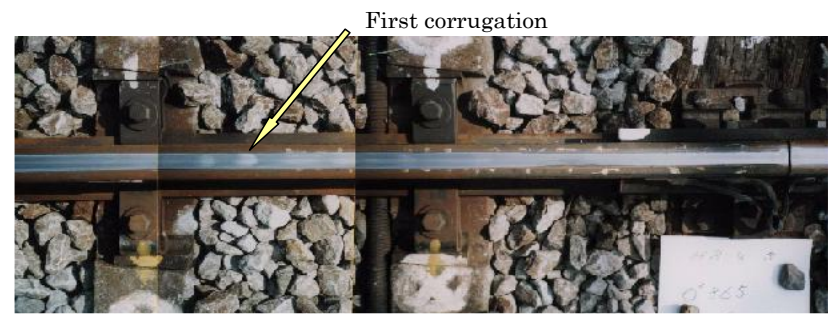

Figure 19. The first low rail corrugations formed on a new rail

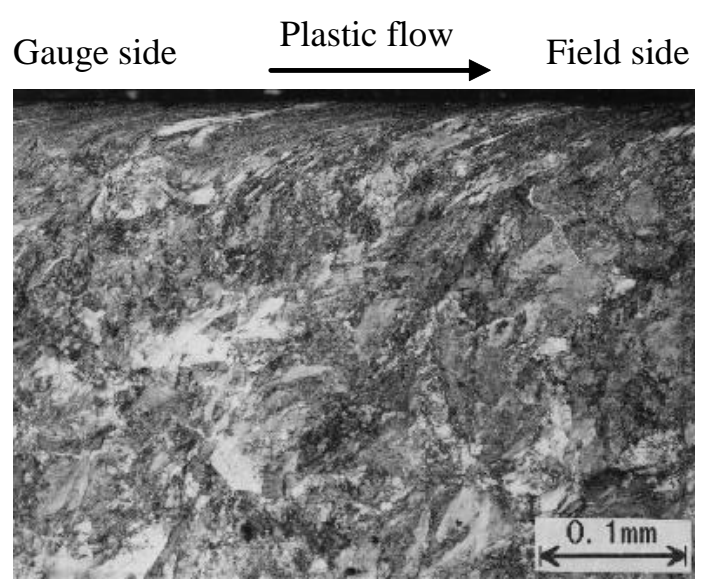

Figure 20. Microstructure of rail surface layer in lateral direction

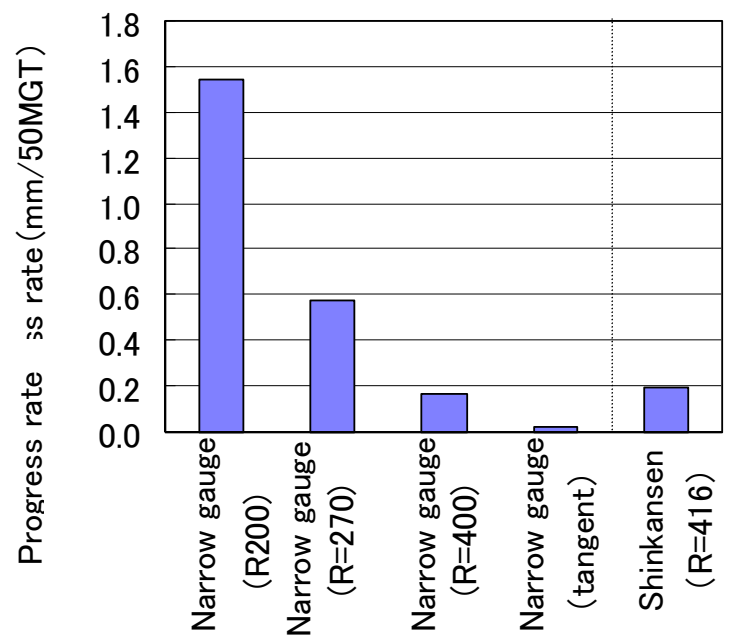

Figure 21. Variation of progress rate of the corrugations with the radius of curvature

Figure 21 shows the variation of progress rate of the corrugations with the radius of curvature. The progress rate is roughly inversely proportional to the radius of curvature. Considering that both lateral creep force caused by a leading axle and longitudinal creep force caused by a trailing axle increase together with the decrease of radius of curvatures, it is not clear which axle has more influence on the formation of corrugations. However, it is not contrary to the possibility of lateral forces influencing the development of corrugation.

\section{(2) Causes of corrugations}

Experimental investigations and microscopic observation indicate that

a) Lateral creep forces of a leading axle play an important role in low rail corrugations.

b) Rail joints can be the main trigger for exciting the fluctuation of Q/P (lateral force / vertical force).

c) The fluctuation of $\mathrm{Q} / \mathrm{P}$ may lead to stick-slip between wheel and rail, and wear takes place to form corrugations.

The fluctuation of $\mathrm{Q} / \mathrm{P}$ based on the vertical force $\mathrm{P}$ variation excited at rail joints and the resonance of rail tilting 
vibration may be the main factors of formation of low rail corrugations, but this proposition cannot be experimentally proven because the fluctuation of $\mathrm{Q} / \mathrm{P}$ cannot be directly measured in situ due to the too short interval of strain gauges installed at a rail which covers usually $200 \mathrm{~mm}$ long. Also, that of $\mathrm{Q} / \mathrm{P}$ cannot be measured by strain gauges installed at a wheel because the signals whose frequencies more than $100 \mathrm{~Hz}$ are filtered due to the resonance of the wheel structure. To understand theoretically the mechanism of low rail corrugations, further study which considers dynamic vehicle / track interaction, curving performance of vehicle, and the lateral stiffness of track is required.

\section{3) Lubrication}

Lubrication between wheel and rail has been adopted to reduce (i) squeal, (ii) wheel flange vertical wear and (iii) rail gauge face wear. Lubrication is used to prevent low rail corrugations at sharp curves. To investigate the effect of lubrication on preventing corrugations, the normal lubricant was applied on the crown of low rails at a sharp curve with a radius of curvature of about $300 \mathrm{~m}$. Investigations were carried out up to about $200 \mathrm{MGT}$ and it was found that no corrugations formed [22]. It has been suggested that lubrication on the crown of low rails has significant effect on increasing safety against wheel flange climb derailment [23]. If the lateral creep force decreases due to lubrication, then the lateral force of high rail, usually called flange reaction, will decrease as well. This means that wheel flange vertical wear and rail gauge face wear should be reduced. On the other hand, lubrication of the rail crown has some risk of wheel sliding. Such significant advantages and risks need to be balanced by choosing a lubricant with an appropriate $\mathrm{COF}$.

On the other hand, the mechanism of low rail corrugations is almost understood but its prediction model has not been established yet. Also, one of most effective solutions to prevent low rail corrugation in sharp curves is considered "friction modifier" which was developed focusing on preventing negative damping phenomenon in traction curve shown in Figure 22 and obtaining positive slope in sliding region of slip ratio [24].

A solid-type lubricant which was named as "friction moderator" to reduce lateral force and squealing noise excited by vehicle negotiating sharp curves was developed. Friction moderator consists of grains of coke whose raw material is artificial graphite crushed to a diameter of $0.2 \mathrm{~mm}$ and appropriately arranged about its graphitization, and

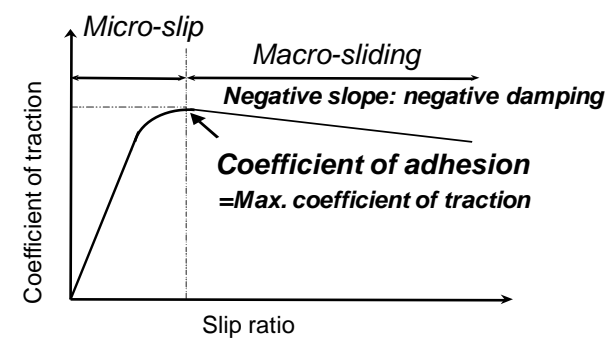

Figure 22. Typical characteristics of traction curve

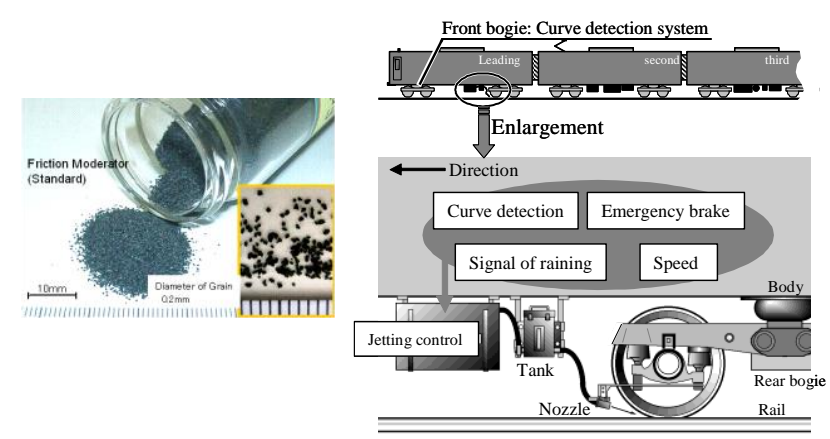

Figure 23. Friction Moderator and Friction Moderating System (on-board system)

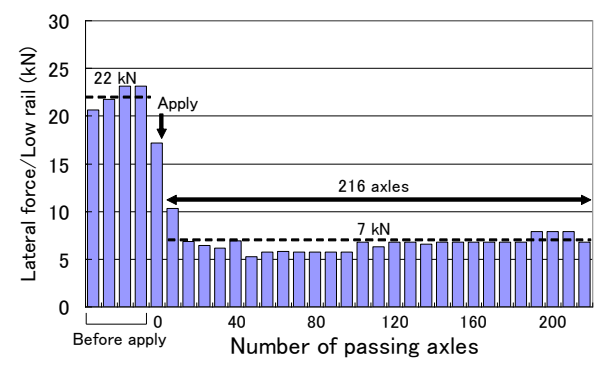

Figure 24. Effect of Friction Moderator (Lubricant) on decreasing lateral force

phenol resin which is adopted as coating for the grains of coke from the aspect of preventing them from catching fire and to aid braking (because phenol resin is used for composite brake shoes). Also, the jetting device was developed with a focus on the arrangement of the nozzle size and air pressure. Figure 23 shows friction moderator and its jetting system on board, which is called as Friction Moderating System (FRIMOS).

Figure 24 shows the lateral forces of the low-rail and high-rail as measured at the track site. In the figure, approximately $22 \mathrm{kN}$ of lateral force on the low-rail before application of the friction moderator decreased to approximately $7 \mathrm{kN}$ after application to the wheel/rail interface on the low-rail side using the jetting device of the FRIMOS that was installed on the test vehicle [25].

\subsection{Long pitch corrugation in the tangent track under salty environmental tunnel}

Figure 25 shows rail corrugations formed on slab track in the ascending slope of salty environmental tunnel, called Shin-Kammon Channel tunnel, of San-yo Shinkansen line [26]. Since they are causing noise and large interacting forces between wheels and rails, a lot of maintenance work such as frequent rail renewal and rail grinding have been spent to cope with those problems.

Figure 26 shows a typical photo of the waveforms and its phase lag of corrugations between left and right rails. In this figure, the wavelength is about $1.2 \mathrm{~m}$ whose frequency calculated by running speed is about $70 \mathrm{~Hz}$ which is almost the same as the resonance frequency of unsprung mass of vehicle supported by track stiffness. Also, there are two 


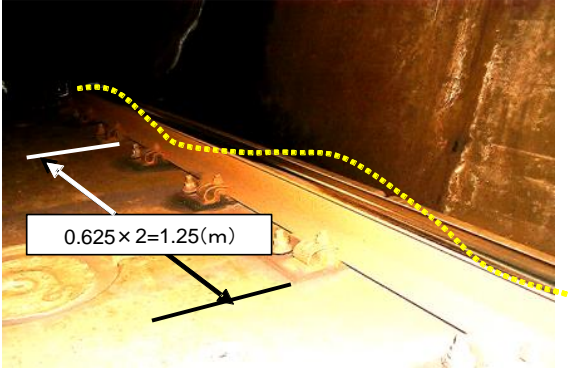

Figure 25. Rail corrugations formed in the ascending slope of ShinKammon Channel tunnel (salt water environmental tunnel)

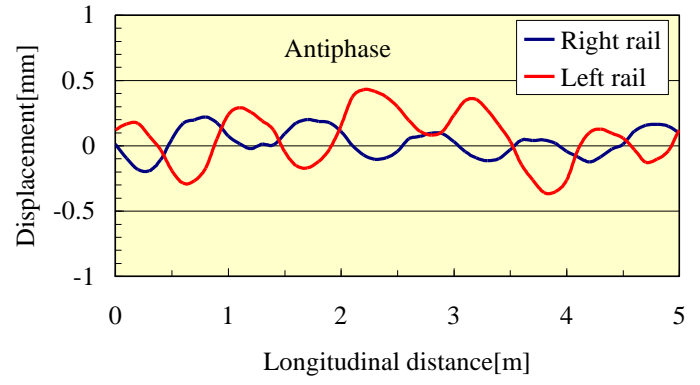

Figure 26. Typical example of the waveforms and its phase lag of rail corrugations

cases about the phase lag between the right rail and left rail corrugations. One is the same phase of both rails and the other is the phase lag of 180 degree between right rail and left rail. Considering those facts, the resonance of unspring mass of vehicle and the rolling frictional vibration of wheelset may have great influence on the mechanism of rail corrugations.

Figure 27 shows the location of rail corrugations observed in ascending slopes of the tunnel. In this figure, corrugations are generated only in ascending slopes not in descending slopes, and in almost tangent track, which suggests the corrugations may be caused by driving wheels not following wheels. According to the findings obtained from the Figs. 26 and 27, the possibility of the following mechanism of the corrugations can be considered.

The maximum traction force which is estimated by wheel load multiplied by adhesion coefficient called the maximum traction coefficient and is almost equal to kinetic friction coefficient in the case of normal dry condition, changes in proportion to wheel load variation. On the other hand, wheels drive on rails with some rolling inertia. Rolling inertia doesn't always follow the variation of maximum

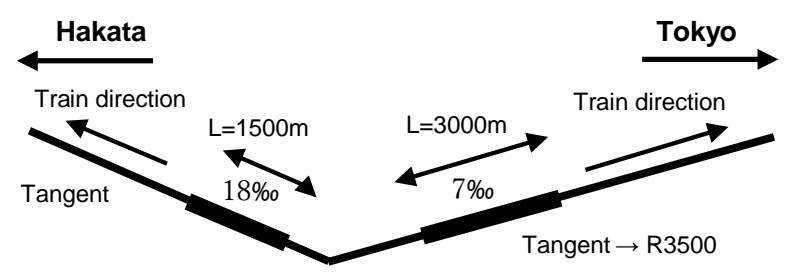

$\mathrm{L}$ : Length of observed corrugations R3500: Radius of curvature of $3500 \mathrm{~m}$

Figure 27. Location of rail corrugations observed in ascending slopes of Shin-Kammon Channel tunnel (upward-slop) traction coefficient depending on the surface conditions of rail and wheel, which induce longitudinal roll-slip phenomenon along rails.

As a result, such a roll-slip phenomenon may cause rail corrugations. In fact, driving force can excess over the maximum traction force depending on wheel load variation and kinetic $\mathrm{COF}$, and wheels can slip on rails very slightly.

To verify the above-mentioned mechanism of rail corrugations, it was desirable that the roll-slip phenomenon of wheel would be directly confirmed from the variation of wheel rotation, however, which was not easy at this moment because the precision of measuring rotational speed of axle was not enough to identify the phenomenon of about $70 \mathrm{~Hz}$. Then investigating the possibility of the roll-slip, the kinetic $\mathrm{COF}$ of rail was measured focusing on rust on the surface of rail due to the atmosphere in the tunnel under the sea to check the appropriately low COF which may induce roll-slip phenomenon.

\section{(1) Plastic flow on corrugated rails}

To confirm longitudinal roll-slip caused by wheel load variation, the longitudinal plastic flow of rail was investigated. Figure 28 shows longitudinal plastic flow on rail surface layer. In this figure longitudinal plastic flow is clearly observed. On the other hand, lateral plastic flow was not observed. This means such large traction force or driving force necessary for a vehicle to ascend a slope, may has a great influence on generating plastic flow and the possibility of roll-slip phenomenon to cause such corrugations.

\section{(2) Influential factors on the maximum traction coefficient}

Next, Figure 29 shows the surface condition of rail crown. In this figure, almost all area of running surface of rail look very rusty. This surface may suggest that $\mathrm{COF}$ measured by sliding probe system may not be evaluated properly because the shape and hardness of sliding probe

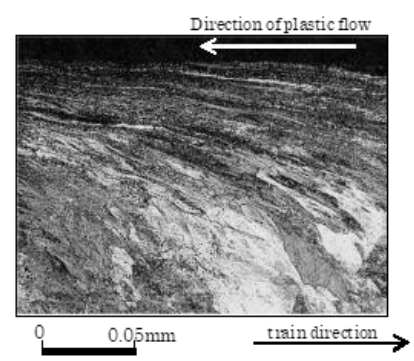

Figure 28. Microstructure of rail surface layer in longitudinal direction

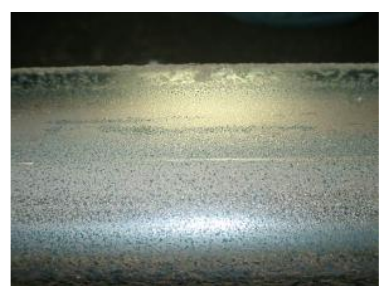

Figure 29. State of top surface of rail 
should be checked from the aspect of suitability of contact interface between sliding probe of measuring apparatus. Accordingly, the measured COF may not be a parameter to evaluate the possibility of sliding. Considering such a situation, the surface substance or oxidized layer of rail crown was focused to investigate the possibility of roll-slip phenomenon.

At first Fourier transform infrared absorption spectroscopy was revised to analyse the surface of rail installed in track in situ but the analytical results were not clearly achieved. Then sample rails were put aside track in a salty environmental tunnel and a dry mountain tunnel which was selected as no corrugation condition to compare with the salty environmental tunnel. The sample rails were exposed in those two tunnels for 6 months to get rust enough for analysis. X-ray diffraction analysis was carried out to investigate the surface substances of sample rails.

Figure 30 shows the analytical results in comparison with the two tunnels. In this figure, some iron oxides and oxyhydroxides were identified, but $\beta-\mathrm{FeOOH}$ was found out only in the case of salty environmental tunnel. Since $\beta$ $\mathrm{FeOOH}$ is the material of low COF, the possibility of rollslip phenomenon can be expected only in salty environmental tunnel. In this study, in situ analysis has not been successful yet, but laboratory analysis, particularly Xray diffraction analysis, played a very important role to recognize the possibility of roll-slip phenomenon leading to the formation of corrugation.

\section{(3) Formation mechanism of rail corrugations in salty environmental tunnel}

Considering the above-investigated results, the factors of mechanism of rail corrugations are considered to be as follows:

(a) Large traction force is generated by driving wheels to climb up the ascending slopes of salty environmental tunnel

(b) Wheel load variation is excited at the irregularity of rail welds. The phase of one side wheel load variation is almost reverse to that of the other wheel.

(c) The maximum traction coefficient between wheel and rail is not large enough because of the small amount

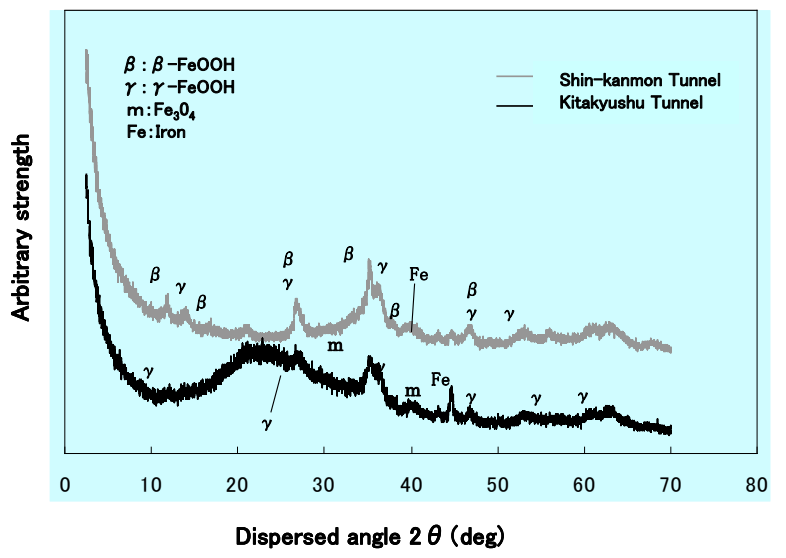

Figure 30. Results of X-ray diffraction analysis of $\beta-\mathrm{FeOOH}$ on the running surface of rail only in salty environmental tunnel.

(d) Roll-slip phenomenon may be induced based on the relationship between the driving force of wheel and the maximum traction force depending on wheel load variation excited at rail welds.

(e) Wheel load variation is excited more by the formation of corrugations and wear amount of corrugation is progressed by the wheel load variation.

Roughly speaking, rail corrugations described here are considered to form under the combination of decreasing the maximum traction coefficient appropriately up to not too small value and not enough value due to rust under the sea tunnel, the variation of the maximum traction force depending on wheel load variation excited at rail welds and the rolling inertia of driving wheels to climb up the ascending slopes in the tunnel.

\section{Concluding Remarks}

This review describes the history of rolling contact fatigue $(\mathrm{RCF})$ defects of rails and two types of corrugations classified focusing on their wavelength and/or frequency formed in Japanese railways and their mitigation strategies from rail maintenance point of view. The concept of mitigation strategy for RCF defects is balance between wear and RCF. The effect of grinding is the same as that of wear. In fact, controlling wear amount is a key word to mitigate $\mathrm{RCF}$ defects with grinding and lubrication. Also, the concept of mitigation strategies for rail corrugations is controlling tribological conditions of wheel/rail interface, reducing lateral resistance (traction coefficient) and increasing longitudinal resistance (traction coefficient) to prevent stick/roll-slip at wheel/rail interface.

Finally, it should be better to control vehicle/track interaction focusing on the combination of vehicle/track dynamic interaction and wheel/rail tribology under the collaboration of vehicle engineers and track engineers who should be encouraged to improve vehicle/track maintenance strategies for advancing vehicle/track maintenance quality and cost reduction.

\section{References}

[1] Nakamura, R., Yamato, H. and Enomoto, S.: Synthetic report on rail dark crack, RTRI Report, No.379, 1963 [in Japanese].

[2] Gidelines to best practices for heavy haul railways operationsInfrastructure construction and Maintenance Issues, International Heavy Haul Associ., June, 2009, pp.3-9.

[3] Smith R.A.: Current Understanding of The Rolling Contact Fatigue Problem in Rails, Imperial College, London, Proceedings of ASIA TRIB 2006 KANAZAWA, JAPAN

[4] Kazamaki, T., et al: Rail shellings in Eidan underground, Tetsudo Senro (First half), 16-5, 1968, pp.27-31

[5] Kazamaki, T., et al: Rail shellings in Eidan underground, Tetsudo Senro (Second half), 16-6, 1968, pp.35-39.

[6] T102 study group : Mitigation measures for rail shelling -1985 annual report - ,RIRI report, A-87-81, 1987 [in Japanese].

[7] Ishida, M., Akama, M., Kashiwaya, K. and Kapoor, A.: The current status of theory and practice on rail integrity in Japanese railwaysRolling contact fatigue and corrugation, Fatigue \& Fracture of Engineering Materials \& Structures, 26, 2003, pp.909-919. 
[8] Ishida, M. and Hua Chen, Franklin, F. : The effect of preventive grinding from the aspect of roughness contact, Journal of Japanese association of railway civil engineers, 38-2, 2000, pp.49-52 [in Japanese].

[9] Inoue, Y. : Mechanism of Shelling Initiation, Journal of Japan Railway Civil Engineering Association, Vol.32, 1994, pp.430-433 [in Japanese].

[10] Ishida, M. and Abe, N.: Experimental Study on Rolling Contact Fatigue from Aspect of Residual Stress, Wear 191, 1996, pp.65-71.

[11] Ishida, M., Abe, N. and Moto, T.: The effect of preventive grinding on rail surface shelling, Quarterly Report of RTRI, 39-3, 1998, pp.136141.

[12] Modern Tribology Handbook, Volume Two, Editor-in-Chief of Bharat Bhushan, CRC press, Sep. 2000, p.1324.

[13] UIC : INNOTRACK, Innovative Track System, www.innotrack.eu, 2010.

[14] Burstow, M. C.: A model to predict and understand rolling contact fatigue in wheels and rails, Proc.of the 7th World Congress on Railway Research (WCRR 2006), Montreal, Canada, 2006.

[15] Dembosky, M., Doherty, A., Urban, C., Walker, R. and Gurule, S.: Management of rolling contact fatigue (RCF) in the UK system: a systems solution, Proc. of 7th World Congress on Railway Research (WCRR 2006), Montreal, Canada. 2006.

[16] Nakamura, T. \& Kitahara, K. : Rail Grinding Tests to Control Rail Failures in Curved Tracks, Journal of Japan Railway Civil Engineering Association, Vol.51, No.3, 2013, pp.36-39 [in Japanese].

[17] Jin, Y., Ishida, M.: Analyses of White Etching Layer Generated on Rail Surface, RTRI report, 19-9, 2005, pp.17-22. [in Japanese].
[18] Grassie, SL: Squats and squat-type defects in rails: the understanding to date Proceedings of the Institution of Mechanical Engineers, Part F: Journal of Rail and Rapid Transit 226, 2012, pp.235-242.

[19] Schilke, M. and Persson, C.: White etching layers on the Stockholm local traffic network, Proc. of CM2012, Chengdu, China, 2012, pp.589596.

[20] Satoh, Y., et al : Evaluation of Bainitic Steel Rail by Durability Tests in Revenue Line, RTRI Report, 22-4, 2008, pp.29-34 (in Japanese).

[21] Tassily, E. and Vincent, N., Rail corrugations: analytical model and field tests, Wear, 144 (1991), 163-178.

[22] Ishida, M. and Moto, T. and Takikawa, M., The Effect of Lateral Creepage Force on Rail Corrugations on Low Rail at Sharp Curves, Wear, 253(2002), 172-177.

[23] Ishida, M. and Nakahara, T., Derailment Accident in Hibiya Line and Tribology, Tribologist, 46(2001) No.7, pp46-53 [in Japanese].

[24] Eadie, D.T., Kalousek, J. and Chiddick, K.C., The Role of High positive Friction (HPF) Modifier in the Control of Short Pitch Corrugations and Related Phenomena, Wear, 253, 2002, pp.185-192.

[25] Ishida, M., Ban, T., and Fukagai, S. Friction Moderating System for Preventing Low Rail Corrugations in Sharp Curves, 8th International Conference on Contact Mechanics and Wear of Rail/Wheel Systems(CM2009), Firenze, Italy, September 15-18, 2009

[26] Ishida, M., Aoki, F., Sone, Y., Ban, T. and Shirouzu, K. (2005), Rail corrugations caused by low coefficient of friction in a submarine railway tunnel, Proc. of World Tribology Congress, Washington, DC, USA, 12-16 Sept., WTC2005-64346. 